is then no longer suitable for the observation of single cells. Nevertheless, I hope that the method will be of use in investigating the laying down of the new cuticle of the regenerating leg.

Department of Zoology,

University of Cambridge. Sept. 9.

${ }^{1}$ Fischer, I., and Gottschewski, G., Naturwiss., 37 (1939).

2 Wigglesworth, V. B., J. Exp. Biol., 14, 364 (1937).

\section{Economic Control of the Relapsing Fever Tick in African Houses}

THE control of the relapsing fever tick, Ornithodoros moubata Murray, which is widespread and alarmingly abundant in many townships and labour camps in East Africa, has hitherto proved uneconomic, owing to the marked resistance of the species to the common insecticides, and the consequent heavy dosage required. I have recently had occasion to carry out trials on a practical scale with a number of 'Gammexane' formulations, and the results have been so promising that it was thought opportune to bring the details of a simple method of treatment to the notice of all who are interested in the control of ticks.

It is a matter of simple experiment to demonstrate the outstanding toxicity of hexachlorocyclohexane to o. moubata. Individuals subjected to the lightest dusting with a commercial dust containing 0.5 per cent of 'Gammexane' begin to lose their power to co-ordinate leg movements after 4-6 hours. They may lose up to 10 per cent of their body weight in twenty-four hours by excessive coxal secretion, by defæcation of milky fluid, and probably also by increased permeability of the tough integument. There is in many cases a darkening of colour, due to the diffusion of ingested hæmoglobin compounds from the gut to the body cavity. The ticks become immobile, except for feeble but persistent, and sometimes rhythmical, leg movements, after periods varying from twelve hours to five days, according to age, and mortalities of $80-100$ per cent result after 8-10 days. In the case of adult ticks, and particularly of gravid females, individuals have shown leg move. ments up to two months after treatment, but any eggs laid have invariably failed to hatch. The parallel action of D.D.T. 5 per cent dust is slower and less effective, although mortalities of $50-80$ per cent have been secured after more than twenty days.

In the field, the most economic treatment has proved to be the 0.5 per cent 'Gammexane' dust, applied directly to the floors and the first few inches of the walls of infested houses. Application is made with a simple shaker such as a cigarette tin of the circular type, at the rate of 3-4 lb. of dust per 1,000 sq. ft. of surface. The results are checked by a standard system of survey, in which a team of five 'boys' searches the floors to a depth of $1 \frac{1}{2} \mathrm{in}$. at random for five minutes. By this means, the infestation figures in a labour transit camp have been reduced from an average of 20 per unit sample to less than $0 \cdot 2$ over a period of nine months. There was evidence that retreatment was required after this time, possibly owing to consistent re-infestation from transit labourers, who commonly carry the ticks in their bedding.

Since the cost of the material used, if prepared by the dilution of the commercial dust concentrate
(2.5 per cent 'Gammexane') with a local diluent, of which the best appears to be a light diatomaceous earth ('Diatomite'), is in the region of $4 \cdot 5 d$. per lb., this treatment should be well within economic bounds for large-scale application. These experiments have been extended to cover an entire township, consisting of approximately 1,200 houses, 50 per cent of which are infested with Ornithodoros, with consequent high incidence of relapsing fever. It may be some time before the effect on fever statistics can be assessed, but the relief from the ticks is already widely appreciated, and the treatment has been officially standardized in several departments in Tanganyika as an advance on any control method previously known.

I am indebted to the Director of Agricultural Production for permission to publish this note. W. F. JEPSON

Entomological Laboratory, Tanganyika Territory

Department of Agriculture, Morogoro. Aug. 20.

\section{Geological Age : the Extreme Antiquity of Pegmatites from Manitoba}

AN inspection of the available data on geological ages determined by the lead method shows that in two areas the pegmatite ages appear to be considerably greater than those of any other Pre-Cambrian pegmatites so far determined. These two areas are located in northern Karelia and south-east Manitoba, Canada.

The geological age of pegmatites from northern Karelia is quite often held to be the greatest age so far determined. Several specimens of uraninite have been analysed ${ }^{1}$ and the ages, which have been recalculated here with the aid of Wickman's graphs', are invariably nearly $1,800 \times 10^{8}$ years, which is the mean of all the determinations. Some specimens of monazite have also been analysed ${ }^{1}$, and although the age of each specimen is about the same (average $2,100 \times 10^{6}$ years), it is somewhat higher than the uraninite age. From these data, the probable age of the pegmatites from northern Karelia is therefore about $1,800-2,100 \times 10^{\mathrm{s}}$ years. Unfortunately, no isotope analyses of the lead in these specimens are known, and it has thus not been possible to compute ages according to $\mathrm{Pb}^{208} / \mathrm{U}^{238}, \mathrm{~Pb}^{208} / \mathrm{Th}^{232}$ and $\mathrm{Pb}^{207}$ $\mathrm{Pb}^{206}$ ratios, which would provide valuable evidence in support of, or against, the above ages for the northern Karelian pegmatites.

Two specimens of uraninite and two of monazite from Manitoba pegmatites have also given high ages, which, recalculated as stated above, range from 1,700 to $2,000 \times 10^{6}$ years. Lead from one specimen of uraninite and one of monazite has been analysed on the mass spectrograph, and serious discrepancies have been found in the 'ages' of these specimens according to whether the ages are calculated by $\mathrm{Pb}^{208} / \mathrm{U}^{238}, \mathrm{~Pb}^{208} / \mathrm{Th}^{232}$ or $\mathrm{Pb}^{207} / \mathrm{Pb}^{206}$ ratios. These ages, taken from $\mathrm{Nier}^{3,4}$, are given in Table 1 .

\begin{tabular}{|c|c|c|c|c|}
\hline \multicolumn{5}{|c|}{ TABLE 1} \\
\hline No. & Mineral and source & $\mathrm{Pb}^{206} / \mathrm{U}^{298}$ & $\begin{array}{c}\mathrm{Pb}^{208} / \mathrm{Th}^{938} \\
\text { age }\end{array}$ & $\begin{array}{c}\mathrm{Pb}^{807} / \mathrm{Pb}^{206} \\
\mathrm{age}\end{array}$ \\
\hline 1 & Uraninite, Huron & $1570 \times 10^{\circ}$ & $1252 \times 10^{6} \mathrm{yr}$ & ..o \\
\hline 2 & Monazite, , ", & $\mathbf{9 1 8 0}$ & 1830 & 2570 \\
\hline
\end{tabular}

